Puroila, A-M. \& Johansson, E. (2018). Toward the fusion of different horizons: Methodological potentials and challenges when exploring values education in Nordic preschools. In E. Johansson, A. Emilson \& A-M. Puroila (Eds.), Values Education in Early Childhood Settings - Concepts, Approaches and Practices (pp. 165-183). Dordrecht, the NL: Springer.

\title{
Towards the Fusion of Different Horizons: Methodological Potentials and Challenges when Exploring Values Education in Nordic Preschools
}

\begin{abstract}
:
This chapter draws from a research project within which researchers from Denmark, Finland, Iceland, Norway, and Sweden investigated values education in Nordic preschools. The project was based on an interpretive methodology in which knowledge was co-constructed with educators and within a cross-national research team, rather than drawn from direct comparisons between the countries. This chapter contributes to the discussions on cross-cultural methodologies by critically exploring the methodological potential and challenges faced in three sub-studies within the Nordic project. We seek an answer to the question: How is it possible to achieve understanding across professional, linguistic, and national borders? Applying ideas from Gadamer's hermeneutic philosophy, interpretation and understanding are approached in terms of the fusion of horizons. On one hand, the study reveals the potential for encounters of different horizons through collaboration between educators and researchers as well as between researchers from different countries. Coming into contact with a different horizon may broaden the fore-understandings of the interlocutors, thus deepening their understanding. On the other hand, the study draws attention to the challenges of understanding, such as the lack of a common language and limitations when using translated texts. Implications for future research are discussed.
\end{abstract}

Keywords: cross-cultural, horizon, Nordic countries, preschool, values

\section{Introduction}

This chapter addresses methodological questions in interpretive cross-cultural research. In a time of increasingly multi-cultural research designs, there is a challenge to critically explore the qualitative methodologies where the aim is to develop a shared understanding in crosscultural studies. Rubenstein-Ávila (2013), among others, calls for contextual and methodological reflexivity and methodological transparency in studies where meaning-making occurs across linguistic, cultural, or social borders. The chapter draws upon a research project on values education in preschools in five Nordic countries: Denmark, Finland, Iceland, Norway, and Sweden (Johansson, Puroila, \& Emilson, 2016). From the early stages of the project, we acknowledged the methodological challenges of cross-cultural research that predominantly rested on large-scale quantitative methodologies and direct comparisons between countries (see McNess, Arthur, \& Crossley, 2015; Osborn, 2004). Therefore, our aim was to develop 
interpretive methodologies in which knowledge is co-constructed with educators and within a cross-national research team rather than drawn from direct comparisons between the countries.

In this chapter, we explore the methodological challenges and potentials we faced in three substudies within the project. These sub-studies utilize research material from all Nordic countries and are published as scientific articles (Einarsdóttir, Puroila, Johansson, Broström, \& Emilson, 2015; Johansson, Emilson, Röthle, Puroila, Broström, \& Einarsdottir, 2016; Puroila, Johansson, Estola, Emilson, Einarsdóttir, \& Broström, 2016). We seek an answer to the question: How is it possible to achieve understanding across professional, linguistic, and national borders in early childhood education research? Applying ideas from Hans-Georg Gadamer's (2004) hermeneutic philosophy, interpretation and understanding within cross-cultural research will be approached in terms of a fusion of horizons. The potential of Gadamer's hermeneutics in cross-cultural research has been noted by several scholars (McNess et al., 2015; Pillay, 2002; Pouliot, 2007; Rubenstein-Ávila, 2013). Even though the chapter focuses on Nordic studies, it is most probable that researchers in different contexts encounter similar questions, such as how to work with partners who do not have the same mother tongue, what the effects are of employing translated research material, or how to interpret research material and achieve understanding across countries (Osborn, 2004; Rubenstein-Ávila, 2013; Waisbord, 2016). Thus, this chapter contributes to methodological discussions of early childhood education research beyond the context of Nordic countries.

\section{Nordic Early Childhood Education (ECEC): Historical and Linguistic Perspectives}

In Gadamer's (2004; 2006) conceptions of interpretation and understanding, the role of language as well as its connectedness to context, history, and tradition are highlighted (Austgard, 2012; Kinsella, 2006; Regan, 2012). Therefore, it is necessary to look to the Nordic context of the sub-studies that are reflected on in this chapter.

Previous research literature maintains that Nordic countries form a homogenous region both geographically and through their common history and shared values (Tjeldvoll, 1998; Wagner \& Einarsdottir, 2008). Historically, Denmark has covered the areas of Norway (until 1814) and Iceland (until 1918), while Sweden has formed a union with Finland (until 1814) and later with Norway (1814-1905) (Tjeldvoll, 1998). Due to the common history, Swedish is still one of the official languages in Finland.

Most of the languages that are spoken in the Nordic countries belong either to the Nordic branch of Indo-European languages or to the Finno-Ugric languages. Danish, Icelandic, Norwegian, and Swedish originate from the same Nordic branch even though these languages have diverged over the last thousand years. However, Danish, Norwegian, and Swedish people can still speak and read each other's languages. Finnish and various Sami languages, belong to the FinnoUgrian language family. Sami languages are spoken in the northern parts of Finland, Norway, and Sweden. In addition, there are other minority languages to be found in the Nordic countries, such as Kven, Torne Valley Finnish, Karelian, Roma, and Sign languages. (Norden, 2016; Wagner \& Einarsdottir, 2008.) Moreover, increasing immigration makes the languages spoken in the Nordic countries even more diverse. Thus, it is obvious that the Nordic countries are multilingual and that the linguistic borders do not entirely follow the borders between the countries. 
Two important concepts have framed the Nordic ECEC over the years: the Nordic welfare model and the idea of child-centeredness (Kristjanson, 2006). High priority has been given to inclusion and the idea that every citizen should have equal access to the welfare and educational systems. The Nordic societies are acknowledged as the worlds' most equal, both from economic and gender perspectives (Moss, 2007). At the same time, ECEC has functioned to support children's learning and development through warm and inclusive social relationships and a play-based and child-centered pedagogy. Democracy, caring, and competence values are to be found in all the Nordic curricula even though they are differently emphasized (Einarsdottir et al., 2015). In sum, one can say that traditionally there has been a strong dedication to social pedagogy rather than academic subjects in the Nordic ECEC, even though these ideas are thought to be challenged in todays' societies (Johansson, 2010).

\section{Towards Understanding Meanings: The Concept of Horizon}

In this article, we draw on Gadamer's ${ }^{1}(2004 ; 2006)$ hermeneutic philosophy to conceptualize the interpretation and understanding of meanings in cross-cultural research. The hermeneutic philosophy has underpinned a big body of qualitative studies where language and the interpretation of texts are in the forefront (Kinsella, 2006). Gadamer also views language as crucial for sharing human experiences and establishing a common ground for understanding. Gadamer $(2004$; 2006) highlights that both the world and the human experience of the world are verbal by nature. Even though Gadamer discusses widely verbal language in terms of speech and conversation, he argues that similar assumptions are applicable to interpreting and understanding texts (Gadamer, 2004). Gadamer (2004) considers that written texts are alienated speech by character and that the hermeneutical task is to transform text back into speech and meaning. Furthermore, Gadamer (2004) argues that interpretation is verbal in such cases when what is to be interpreted is not in linguistic form, for example, musical compositions, visual arts, or dramatic performances.

Gadamer (2004) clearly rejects an instrumental approach to language, where signs, words, and concepts are considered merely tools for communication. Rather, he emphasizes that language is connected to history, culture, and tradition as well as to the situation where language is used (Austgard, 2012; Pillay, 2002). Gadamer (2004) maintains that understanding another is not possible by getting inside the person or reliving his/her experiences; rather, he views conversation as a process of coming to an understanding. For Gadamer (2004), the process of understanding is not conveying information from one to another; understanding is interpretation that takes place in an ongoing dialogue with one another and oneself. Respectively, understanding text is a dialectical process that takes place between the text and the interpreter.

Gadamer's (2004) conception of horizon is one potential way to approach the dialectical process of interpretation and the understanding of meanings (Puroila, et al., 2016; RubensteinÁvila, 2013). Gadamer (2004, p. 301) defines a horizon as "the range of vision that includes everything that can be seen from a particular vantage point". For Gadamer, a person who has a narrow horizon tends to over-value the matters that are nearest to her/him. Respectively,

\footnotetext{
${ }^{1}$ Gadamer developed his philosophical perspective in his main publication "Wahrheit und Methode. Grundzüge einer philosophischen Hermeneutik " in 1960. In this study, we use the second, revised version where the English translation has been revised by Joel Weinsheimer and Donald G. Marshall (Gadamer, 2004).
} 
expanding one's horizon means that one learns to look beyond the nearest matters (Gadamer, 2004).

In Gadamer's philosophy, the horizon has a two-fold function for interpreting and understanding meanings. On one hand, human beings' capacity to understand meanings is delimited by their horizons. When trying to understand other people or texts, we do not approach them objectively; rather, we are tied to our prior experiences and presuppositions. On the other hand, the horizon is not a stable and rigid boundary; we are invited to expand the horizon by going beyond and advancing further. As Gadamer puts it, the horizon is "something into which we move and that moves with us" (Gadamer, 2004, p. 303). Gadamer thus challenges us to become conscious about our prejudices and the history that influences our horizons. This requires being open to questions that arise when we meet something that does not accord with our expectations (Austgard, 2012; Kinsella, 2006; Regan, 2012).

Encountering another human being provides an opportunity to meet new horizons and expand one's own horizons. Understanding occurs as a fusion of horizons: interlocutors achieve a common understanding about a subject matter in conversations (Gadamer, 2004, p. 370). This transforms the views of both parties (Gadamer, 2006). Similarly, the fusion of horizons may occur when interpreting texts: the horizons of the text and the interpreter meet in a dialogue (Siljander, 2011). However, this does not mean that any single interpretation would be correct or that the horizons of the interpreter and the object of interpretation were identical (Gadamer, 2004; also McNess et al., 2015; Siljander, 2011). Understanding is a dialectical process that takes place as an interpretational movement between the interpreter's prior understandings and the new horizons (Austgard, 2012). In what follows, three sub-studies will be reflected on in the light of Gadamer's philosophy.

\section{Deepening Understanding of Values Education in Nordic preschools: Three Sub-studies in the Nordic project}

The methodology of the Nordic research project was based on combining the participatory action research methodology of national studies with a cross-cultural orientation at the Nordic level. This methodology enabled working at several levels: individual educators, preschool communities, societies, and the Nordic countries. In this chapter, we reflect on three sub-studies conducted within the project (Einarsdottir, et al. 2015; Johansson, et al., 2016; Puroila, et al., 2016). These sub-studies approached values education in Nordic preschools from different angles: educational policies, the communication of values between educators and children in preschools, and educators' interpretations on educational practices from the perspective of values. As the table 1 shows, there were differences in generating, analyzing, and interpreting the research material as well as reporting the findings. 
Table 10. 1. Three sub-studies from the Nordic project

\begin{tabular}{|c|c|c|}
\hline & Study 1 & Study 2 \\
\hline $\begin{array}{l}\text { Aim of the } \\
\text { study }\end{array}$ & $\begin{array}{l}\text { *to gain an understanding } \\
\text { about values education in } \\
\text { preschools as constructed in } \\
\text { central policy documents in } \\
\text { the Nordic countries }\end{array}$ & $\begin{array}{l}* \text { to explore how rights were } \\
\text { argued for and } \\
\text { communicated between } \\
\text { educators and children and } \\
\text { how gender was related to } \\
\text { rights in the participating } \\
\text { Nordic preschools }\end{array}$ \\
\hline $\begin{array}{l}\text { Research } \\
\text { material }\end{array}$ & $\begin{array}{l}\text { Policy documents: } \\
\text { *National curricula from } \\
\text { each Nordic country }\end{array}$ & $\begin{array}{l}\text { Video-observations from } \\
\text { conflict situations in } \\
\text { preschools } \\
* 25 \text { conflict situations, } 5 \\
\text { from each Nordic country }\end{array}$ \\
\hline Educators' role & $\begin{array}{l}\text { *Educators did not } \\
\text { participate in this sub-study }\end{array}$ & $\begin{array}{l}\text { *Educators participated in } \\
\text { situations that were video- } \\
\text { recorded and used as a } \\
\text { research material }\end{array}$ \\
\hline
\end{tabular}

\section{Study 3}

*to deepen cross-cultural understanding regarding how educators interpret early childhood practices from the perspective of values in Nordic preschools

Group discussions *10 group discussions, 2 from each Nordic country

*Educators read a description about a dressing episode in a Swedish preschool and talked about it in group discussions *in some countries, educators commented interpretations made by researchers

The transcriptions about the conflict situations were translated into English

*Hermeneutic analysis
The English translations were used
Multiple translations *the dressing episode was translated into educators' mother language *group discussion in educators' mother tongue *transcriptions from the group discussions were translated into English

*Inductive, data-driven hermeneutic analysis

1) Researchers analyzed data from their own country (nation-level analysis) 2) Researchers analyzed data from another country (crossnational analysis) analysis

*Language-based quantitative analysis

Analysis and Nation-level analysis: interpretation

$\begin{array}{ll}\text { Analysis } & \text { *Thematic qualitative } \\ \text { methods } & \begin{array}{l}\text { analysis } \\ \text { *Language-based } \\ \text { quantitative analysis }\end{array} \\ \text { Analysis and } & \begin{array}{l}\text { Nation-level analysis: } \\ \text { interpretation }\end{array} \\ & \begin{array}{l}\text { Researchers analyzed and } \\ \text { interpreted data from their } \\ \text { own countries }\end{array}\end{array}$

1) Initial analysis:

Identifying, transcribing, and interpreting 1 conflict situation from each country (national)

2) Discussing four different conflict situations in groups (cross-national)

3) Identifying and transcribing 5 conflict situation (national) 4) Three responsible researchers analyzed the whole material (crossnational analyses) 


\begin{tabular}{|c|c|c|}
\hline $\begin{array}{l}\text { Reporting the } \\
\text { findings }\end{array}$ & $\begin{array}{l}* \text { Researchers wrote the } \\
\text { preliminary findings from } \\
\text { their own country } \\
* \text { Two researchers drew the } \\
\text { findings together }\end{array}$ & $\begin{array}{l}\text { *Three researchers wrote } \\
\text { preliminary findings (cross- } \\
\text { national) } \\
\text { *The preliminary findings } \\
\text { were elaborated within the } \\
\text { Nordic research group }\end{array}$ \\
\hline
\end{tabular}

\author{
*One researcher drew \\ national and cross-national \\ analyses together and wrote \\ preliminary findings \\ *The preliminary findings \\ were elaborated within the \\ Nordic research group
}

\section{Study 1: A Study About Democracy, Caring, and Competence Values in Nordic ECEC Curricula}

The study 1 focused on values in ECEC policies in the Nordic countries (Einarsdottir, et al., 2015). A closer look was taken at three value fields within the policy documents: the values of democracy, caring, and competence. The research material consisted of national curricula for early childhood education that were translated into English. The researchers were able to familiarize themselves with the curricula of the other Nordic countries.

In terms of cross-cultural research methodology, a significant strategy was that researchers from all countries were involved in the analysis process. In practice, researchers were responsible for analyzing the material of their own country. First, the core curricula were analyzed qualitatively basing on the ideas of the thematic analysis (Braun \& Clarke, 2006). In addition, a quantitative, language-based analysis was applied to the study (Laugharne \& Baird, 2009). The researchers decided together the keywords related with democratic, caring, and competence values to be analyzed in the curricula. The researchers from each country identified both the frequencies of the key words and the proportion of the words in relation to the total number of words in the curricula. Researchers wrote the preliminary findings from their own country.

After the nation-level analyses, two researchers (Einarsdottir and Puroila) drew the national summaries and findings together with the aim to reflect on the findings within a Nordic framework. They provided the preliminary research findings at the Nordic level for the manuscript of the article. The manuscript, including the interpretations on findings, was discussed within the Nordic research group. Researchers had an opportunity to comment and revise the interpretations drawn from their own country. Finally, two researchers (Johansson and Emilson) reflected on the findings and drew conclusions with the help of other researchers from the Nordic countries.

The researchers concluded that the study offered some insights into the similarities and differences of values in the ECEC curricula in the Nordic countries. The researchers addressed also the methodological limitations of the study. Referring to the quantitative analysis, they noted that the meanings of the texts are not only constructed through the choice of words but also how the words are used in different contexts. The quantitative analysis that was based on counting selected words did not enable achieving such context-specific meanings. The researchers also drew attention to the use of translated texts and the challenges in the conceptual and linguistic equivalence when crossing the borders between languages. Therefore, the researchers viewed the findings of the study suggestive and called for further research. 


\section{Study 2: A Study About Rights Communicated Between Educators and Children}

The study 2 explored the communication of values in preschools with a special focus on rights and gender in interactions between educators and children (Johansson, et al., 2016). Three main authors (Johansson, Emilson, and Röthle) took responsibility for guiding the research process and involving researchers from all Nordic countries in various phases of the study. When planning the study, the researchers in the Nordic group agreed to employ video-observations from conflict situations as research material, as such situations provide opportunities for different opinions and involve power and emotions (Johansson \& Emilson, 2016). Conflict situations were defined in a broad sense, as events in which some kind of confrontation, or encounter, between ideas, values, or acts, may take place in the interactions between educators and children. The interpretations of the research material were conducted through different phases and employing both insider and outsider perspectives (Osborn, 2004).

First, each national research team reviewed their observational data (between 20 -70 hours of video observations) to identify and transcribe one conflict situation. The researchers discussed their reflections on the chosen situations and wrote down their interpretations. This initial part of the analysis focused on the insider perspectives and served as a preparation for next step in the analytical process. The second step was to discuss five conflict situations, one from each Nordic country, in cross-national groups in a Nordic workshop. The intention was to create cross-cultural encounters between horizons (Gadamer, 2004) and to employ insider and outsider perspectives when interpreting the research material. These workshops served to create joint knowledge formation and shared understandings of methodological and interpretative issues. It appeared that there were many similarities in the interpretations within the crossnational groups and between the groups as well. Third, each national research team identified, transcribed, and translated into English five conflict situations for the further analyses. The researchers responsible for the study continued the analyses. The research material was treated as a whole, being analyzed in a hermeneutic process (Ricoeur, 1988). In this part of the analyses, requests from the responsible authors were addressed to the national teams asking for more information on how to interpret single situations. Researchers from all Nordic countries were invited to read and comment on the draught paper and some further changes were made.

In sum, the various encounters between the teams of researchers in the analytic process considered the phase of data collection and how to produce trustful and rich data. The researchers experienced the importance of clarifying translation of meaning, as well as discussing the relevance of interpretations of concepts (for example conflict, rights) in the transcription phase. In the further analyses, the interpretation process allowing for insider and outsider perspectives was important to reach both variations and similarities in the understanding of rights across the participating preschools. The dialectical process between national and cross-national data and insider and outsider perspectives gave rise both to new thoughts and familiarity. This analytic process can be described as a collective space for the construction of knowledge (Kemmis \& McTaggart, 2005) inviting researcher to cross-national encounters, clarification and collective creation of meaning.

\section{Study 3: A Study About Educators' Interpretations of Values in Nordic Preschools}

The study 3 explored educators' interpretations on early childhood practices from the perspective of values (Puroila, et al., 2016). The study employed two-level textual material. At 
the core of the study, there was a dressing episode observed in a Swedish preschool and transcribed into text (Johansson, 2003). This episode was used to inspire discussions about values in the participating preschools in all Nordic countries. In Iceland, Norway, and Finland, the episode was translated into practitioners' mother tongue while in Denmark and Sweden the Swedish text was used.

The educators read through the text concerning the dressing episode. Group discussions were organized in each participating preschool for the educators to talk about the dressing episode with their colleagues and the researchers. The main research material of the study consisted of tape-recorded and transcribed group discussions. Material from ten group discussions, two from each Nordic country, were used in the study.

A significant strategy for the cross-cultural research methodology was that the research material was analyzed both nationally and cross-nationally. The analysis was implemented as an inductive, data-driven process (Pouliot, 2007) that proceeded from national analysis to crossnational analysis and finally to drawing findings together at the Nordic level. First, researchers analyzed the group discussion material produced in their own country. Second, researchers analyzed material from another Nordic country. Third, the responsible researcher (Puroila) drew together the findings by going back and forth between the research material and the national and cross-national interpretations. She also wrote preliminary findings to the manuscript of an article. Finally, the preliminary findings were discussed and elaborated within the Nordic research team. The researchers had an opportunity to comment and revise the interpretations drawn from their own country.

The researchers discussed the potentials and challenges of cross-cultural methodology employed in the study. They found that organizing group discussions around the dressing episode created a shared space for the educators and researchers to co-construct knowledge about values. Using the same text in different Nordic countries provided a means of exploring the similarities and differences in interpretations. The researchers raised the use of translated texts as a methodological challenge of the study. The researchers suggested that the double analysis strategy provided a means to diminish the risks of misinterpretations and misunderstandings that are attached with using translated texts.

\section{Potentials and Challenges in Cross-cultural Studies}

\section{Crossing Linguistic Borders: Working with Foreign Language and Translations}

The Nordic research group consisted of researchers from five Nordic countries. In each country, most of the researchers were born in their respective countries and had the same mother language. However, there were some researchers who had lived in different countries, they knew well the early childhood systems of many countries, and they managed to use different languages. To paraphrase Gadamer (2004), they had lived within two or more languages. Regardless of the researchers' different backgrounds, the national research teams were able to communicate in the main language of the country. At the Nordic level, the fact was that we did not have a common mother tongue, yet the Swedish, Norwegian, and Danish researchers were able to communicate by using their own languages. Due to the lack of common mother language, we decided to use English in the research collaboration. All of the researchers were 
in the same situation, i.e. we were challenged to create a common understanding through using English, which was not our mother language. Working with a foreign language meant some limitations in the research work, as we could not manage all the nuances and connotations of the English language. We would surely be able to express ourselves in a richer way in our mother language.

Another significant matter connected with language was that we used translated texts as research material. This was also the case in the sub-studies described above. Using translated texts appeared both as a potential and a challenge. On one hand, using translated texts allowed the researchers to share research material - to read and analyze texts that were produced in all Nordic countries. Reading and interpreting material from another country was sometimes thought-provoking. A good example is what happened when analyzing the curricula from the Nordic countries (study 1). When reading the first sentence of the Swedish core curriculum, "Democracy forms the foundation of the preschool" (Curriculum for preschool, 2011 [1998], p. 3), a Finnish researcher got a feeling of strangeness. She began to question how the concept and value field of democracy appears in the Finnish core curriculum. The analysis revealed that the term "democracy" was not at all mentioned in the Finnish core curriculum (Einarsdottir et al., 2015). This is how encountering a new horizon provided opportunities to expand one's own horizon and deepen understanding about one's own context (Gadamer, 2004). It is notable that meeting a new horizon was possible even though the text that was read and interpreted was a translated one.

On the other hand, the linguistic equivalence formed a methodological challenge when working with translated texts. In the light of Gadamer's philosophy, translating speech or text from one language to another is much more than a technical matter. This is because language conveys culturally loaded meanings and the translator's task is to translate these meanings to be understood in the other language context. Gadamer (2004) argues that there remains a gap between the original language and the translated language - a gap that cannot be completely closed. Therefore, translations need to be understood as interpretations: "it is necessarily a recreation of the text guided by the way the translator understands what it says" (Gadamer, 2004). This is one of the crucial challenges faced by researchers who have been engaged in crosscultural studies (see Osborn, 2004; Puroila et al., 2016; Rubenstein-Ávila, 2013).

We used different strategies to meet the challenges of using translated texts. In the first substudy, the researchers analyzed texts of the curricula and provided preliminary findings from their own country. Even though they were working with translated texts, they had the chance to go back to the original texts and crosscheck how well the translated texts captured the meanings of the original texts. In the second sub-study, the analysis and interpretation was based on combining insider and outsider perspectives in the initial phase of the analysis. In practice, a sample of the research material was interpreted first by mixed groups of Nordic researchers and then by national research teams. As these initial analyses illuminated congruent interpretations, the entirety of the research material was treated as a whole and analyzed by three researchers from two countries (also Alasuutari \& Markström, 2011). In the third substudy, a double analysis strategy was used, which meant that all of the material consisting of translated texts was analyzed twice. This strategy allowed the researchers to analyze the material both from inside and outside the national and linguistic contexts. In all of the substudies, crucial for cross-cultural methodologies and the credibility of the interpretations was the collaboration among the Nordic research group. In all of these studies, the researchers had the chance to examine the relevance of the interpretations made from their own country. To sum up, the interpretation occurred as a dialectical process through moving between different 
horizons: between the original texts and translated texts, between researchers and texts, and in conversations between researchers from different Nordic countries (also Austrgaard, 2012).

\section{Crossing Professional Borders: Researchers' and Educators' Role in Knowledge Construction}

In the entire Nordic project, most of the sub-studies were based on the participatory action research processes that were conducted in the participating preschools. The study on the Nordic core curricula (study 1) was the only sub-study in which the educators did not participate. Thus, the collaboration between educators and researchers formed a crucial part of the methodology of the project. In the light of Gadamer's philosophy, the crucial methodological questions include: How can understanding between researchers and educators be achieved? What is the role of educators and researchers in generating knowledge?

Gunzenhauser (2006) addresses the limitations of positivist and post-positivist approaches that highlight researchers as "knowers" and participants as objects to be "known". He calls for viewing knowledge generation as a co-constructive process where both parties have a role. This means a challenge to enhance participants' role and ownership in the research process (Madsen, 2013). Participatory methods have been seen as a potential means to enhance participants' ownership in the research process (McNess et al., 2015; Milligan, 2016). In the Nordic project, the national sub-projects were methodologically based on a participatory action research model, which aims to both create knowledge and contribute to change (Greenwood \& Levin, 2007). Change in the Nordic project referred to the educators' growing recognition of values and their developmental work towards values education in preschools.

Within the action research processes, the researchers and educators collaborated over approximately two years. The researchers' role was to challenge, encourage, and support the educators in reflecting upon values and values education. The educators' role was to identify issues that needed to be developed and to work towards the developmental process in their settings. Most probably, the level of the educators' participation in generating knowledge varied between the countries. In all of the Nordic countries, the educators participated in producing the research material. In Finland, for instance, the educators' participation went beyond producing research material as they were invited to analyze and interpret material and comment on the interpretations made by researchers.

It is obvious that there were both shared aspects and differences in the educators' and researchers' horizons concerning the research topic. On one hand, the researchers collaborated with the educators in their own country, which means that they shared the linguistic and societal context. More importantly, both researchers and educators worked in the field of ECEC even though they had different tasks and responsibilities. Most of the researchers had long explored early childhood matters in their own country and internationally. They had had opportunities to increase their understandings and broaden their horizons about daily life in preschools. Moreover, some researchers had worked as kindergarten teachers, which helped them put themselves into the educators' place. Thus, it is arguable that the educators and researchers shared to some extent the educational realities in their national contexts, a condition which involves potential for developing shared understanding (also Milligan, 2016).

On the other hand, the educators and researchers had different vantage points (Ellström, 2008) even though they worked in the same field. In the educators' horizons, educational practices 
and encounters with children and parents were the nearest matters. The researchers, in turn, lived in the midst of academic tasks, such as applying for funding, collecting and analyzing research material, writing publications, and giving presentations at scientific conferences. These matters were more or less far from educators' daily experiences. Doubtless, this had consequences for how researchers were positioned in the researcher-educator relationships, as the participants tended to regard the researchers as authorities who have expertise and knowledge that they themselves lack (Madsen, 2013; Suwankhong \& Liamputtong, 2015).

The aim of deepening understanding - fusing the different horizons - was inherently embedded in the action research process. Therefore, much space for conversation was created among the educators and between the educators and researchers (cf. Gadamer 2004). Group discussions (study 3) provide an example of a forum where educators and researchers engaged in conversation, the purpose of which was to interpret and understand early childhood practices from the perspective of values. Arranging the group discussions around a concrete pedagogical situation implies the researchers' attempt to promote equality between researchers and educators - to meet the educators on a ground that was familiar to them. After the group discussion situations, the tape-recorded discussions were transcribed into texts. The study continued as a dialectical process, where the researchers attempted to interpret and understand the text, i.e. fuse the horizons of the text and their own horizons (see Siljander, 2011). As the researchers could develop their understanding about how values were embedded in the group discussions, it is reasonable to argue that some kind of fusion of horizons had occurred.

However, we cannot claim that the educators' and researchers' interpretations were identical (Gadamer, 2004; also Siljander, 2011). The new understanding was a result of a process where both educators and researchers had a crucial role; without either of the parties the study would not be possible. Nor can we argue that the action research process led the researchers to an insider's position in the preschool communities. Despite our honest willingness to encounter the educators on an equal base, we cannot escape the fact that we as researchers were responsible for many important decisions in the research process (see also Madsen, 2013; Puroila \& Johansson, Chapter 9 of this book). For instance, we chose the research field to be explored, set the schedule for the entire research process, decided what to bring from the national sub-studies to the Nordic level analyses, and mostly wrote the research articles.

\section{Crossing National Borders: Working In-Between National Cultures}

The design of the Nordic project required working both at the national and the cross-national levels. At the national level, the action research studies were based on cooperation between educators and researchers and among the research team within the same country. Working at the Nordic level both demanded and enabled crossing the national borders between countries.

Previous literature on cross-cultural methodologies challenges us to consider whether a researcher has an insider's or an outsider's role in the cultural context under study (McNess et al., 2015; Milligan, 2016; Rubenstein-Ávila, 2013; Suwankhong \& Liamputtong, 2015). Sharp criticism has been addressed to the hegemony of universal models and methodologies developed in western academic communities and applied to studies all over the world (Pillay, 2002). Rubenstein-Ávila (2013) refers to a growing body of studies where researchers, who are native to the communities they explore, question researchers' rights and authority to study "the other" (p. 1041). Suwankhong and Liamputtong (2015) suggest that an insider status enables 
researchers to get closer to the participants and create a deeper understanding of the sociocultural context of the research setting.

In the sub-studies reflected on in this chapter, the researchers and educators collaborated within each country. The researchers thus had an insider status when it comes to the sociocultural context of the national sub-studies. Crossing the national borders occurred when the researchers analyzed and interpreted the research material that was produced in the other Nordic countries. In sub-studies 2 and 3, the insider's and outsider's perspectives were purposely employed during the analysis process. On one hand, the aim was to utilize the potential of situations where researchers meet new horizons. As Suwankhong and Liamputtong (2015) remark, an outsider position might enable researchers to see perspectives that the insiders fail to see. On the other hand, we attempted to minimize the potential risks of misinterpretations and misunderstandings if the research material was analyzed solely without understanding the tradition and the culture where the material was produced. In interpreting and understanding meanings across cultures, we were challenged not only to understand what was said in a literal sense "but also the underlying meaning of historically and culturally embedded discourse" (McNess et al., 2015, p. 306).

Considering the researchers' insiderness and outsiderness in the context of the Nordic project requires questioning the similarities and differences between the Nordic countries. As noted earlier, the Nordic countries are often understood as a homogenous region due to their common history, common geographic location, and the common values of equality, democracy, and solidarity (e.g. Tjeldvoll, 1998; Wagner \& Einarsdóttir, 2008). On a global scale, all Nordic countries belong to western, democratic societies and to wealthy, developed worlds. From the perspective of Nordicness, all of the researchers and educators participating in the project can be understood as insiders. Karila (2012), however, calls for taking into account the differences between the Nordic countries, arguing that each country has its own political, geographic, and economic history. Also the research findings and experiences from the Nordic project challenge us to go beyond the simplistic views of Nordic sameness. It is obvious that there are both similarities and differences between the countries. Moreover, there is increasing variation within each country, as the Nordic societies are becoming more pluralistic and multicultural due to the globalization and increasing immigration. Thus, the basis for being an insider or outsider in relation to national cultures is becoming more complex and needs to be critically reconsidered.

\section{Concluding Remarks}

The purpose of this chapter has been to critically reflect on methodological questions involved in interpretive cross-cultural research. Drawing on three sub-studies from the research project on values education in Nordic preschools, the chapter has discussed the potentials and challenges when working across linguistic, professional, and national borders (Johansson et al., 2016). In accordance with recent research literature on cross-cultural methodologies (e.g. McNess et al., 2015; Milligan, 2016; Rubenstein-Ávila, 2013), we have attempted to create reflexivity and transparency in the methodological choices that often have remained unproblematized, such as working with foreign languages, employing translated texts, creating collaborative relationships between participants and researchers, and interpreting research material across countries. These questions have been explored in connection with Gadamer's hermeneutic philosophy and examples from the sub-studies of the Nordic project. In doing so, the chapter both adheres to contemporary discussions on cross-cultural methodologies and 
raises challenges that have rarely been addressed in the field of early childhood education research.

First, the chapter draws attention to the significance of language when conducting interpretive cross-cultural studies. In the light of Gadamer's hermeneutics, interpreting and understanding are essentially language events. When aiming to achieve understanding across linguistic borders, the obvious challenge is the lack of a common language. In the current academic community, the English language has become the lingua franca of educational researchers, i.e. a common tongue for people who speak various different languages. This was also the case in the Nordic project. Creating a common langue is a prerequisite for communication between researchers from different countries, and it enables researchers to explore material that is produced in another country. The promise of academic globalization and employing translations is to "expand intellectual horizons and enrich knowledge" (Waisbord, 2016, p. 870). Another side of the coin is that translations entail epistemological and cultural issues that go beyond mere linguistic matters. This chapter calls for further exploration upon the following questions: How can understanding about nuanced cultural meanings be achieved when researchers operate with foreign languages? What is missed when the research material is translated into another language?

Second, our reflections on the three sub-studies challenge us to go beyond the juxtaposing between insider/outsider positions when crossing professional and national borders. Traditionally, the question of researchers' insider/outsider positions has been addressed in two different ways. There is a long scientific tradition drawn from positivism and post-positivism, where researchers' distance, neutrality, and objectivity - outsiderness - in relation to the participants are considered requirements for the validity of the study (Denzin, 2009). On the contrary, there are discussions where researchers' outsider position has been questioned especially in cross-cultural studies. Researchers who explore and interpret people across cultures are criticized as being guilty of colonialism and "othering" participants (Pillay, 2002). In the sub-studies that were reflected on, the educators and researchers had both shared and different aspects in their horizons - they had both insiders' and outsiders' positions depending on the situation. All the educators and researchers worked in the field of early childhood education and shared the Nordic context, even though their professional tasks and national contexts varied. We noted that employing participatory methods and working in a multinational research team and research context provided fruitful opportunities for moving between different positions and learning from each other. This meant a condition of working in a space in and between different professional and national cultures. The notions drawn from this study support Milligan's (2016) idea of the potential of an inbetweener's position in cross-cultural research. This requires two-fold vantage points: both being immersed in and taking reflective distance from the phenomenon and context under study (McNess et al., 2015; Milligan, 2016). Thus, we suggest that looking at the phenomenon under study both from near and far promote the generation of knowledge and a deepening of understanding across professional and national borders.

Third, our reflections on the three sub-studies challenge us to reconsider the implicitly maintained idea of homogenous cultures that are enclosed by national borders. In the era of ongoing globalization, migration, and social media, people with different ethnic, linguistic, and cultural backgrounds have been brought into a closer contact with each other than ever before in the history of humankind. The borders between countries and nations have become lower and sometimes even blurred. This chapter shows that the question concerning the similarities and differences between the Nordic countries is also a complex one. Without any doubt, the 
Nordic countries are part of the increasingly multi-cultural, multi-linguistic, and pluralistic world. This situation challenges us to scrutinize to what extent the idea of the shared Nordicness is still relevant. Keeping in mind the growing diversity within the Nordic societies, it is astonishing that in our sub-studies, the educators and educational researchers from different Nordic countries ended up with very similar interpretations when looking at daily situations in ECEC settings (Puroila et al., 2016; Johansson et al., 2016). This notion requires critically rethinking the conception of culture that has traditionally been understood as shared beliefs, norms, and patterns of behavior framed by people's belonging to a nation (Anderson-Levitt, 2012). In accordance with some recent scholars, we suggest that a more complicated understanding of culture is needed - that is, how a variety of factors influence and shape people's interpretations and understandings of their lives (Amelina, Faist, Glick Schiller, \& Nergiz, 2012; Anderson-Levitt, 2012). In addition to nationality or ethnicity, several other aspects are meaningful for how people interpret human life, such as age, gender, and generation. In the sub-studies that were reflected on in this chapter, professionality in early childhood education appeared as significant for educators' and researchers' opportunities to achieve shared understandings - to fuse their horizons.

To conclude, when searching for deeper understanding across linguistic, professional, and national borders, we encounter several fundamental questions that are rooted to our assumptions about human beings, language, and culture. Understanding across borders is possible, but it requires empathy, openness to others, and welcoming differences rather than rejecting them.

\section{Acknowledgements}

The study is part of the research project "Values education in Nordic preschools - Basis of Education for tomorrow", funded by NordForsk research programme "Education for Tomorrow" (project number 53581).

\section{References}

Alasuutari, M., \& Markström, A-M. (2011). The making of the ordinary child in preschool. Scandinavian Journal of Educational Research, 55(5), 517-535.

Amelina, A., Faist, T., Glick Schiller, N., \& Nergiz, D. (2012). Methodological predicaments of cross-border studies. In A. Amelina, D. Nergiz, T. Faist, \& N. Glick Schiller. (Eds.), Beyond Methodological Nationalism. Research Methodologies for Cross-border Studies (pp. 1-19). New York, NY: Routledge.

Anderson-Lewitt, K. (2012). Complicating the concept of culture. Comparative Education, 48(4), 441-454.

Austgard, K. (2012). Doing it the Gadamerian way - Using philosophical hermeneutics as a methodological approach in nursing science. Scandinavian Journal of Caring Sciences, 26(4), 829-834.

Braun, V., \& Clarke, V. (2006). Using thematic analysis in psychology. Qualitative Research in Psychology, 3(2), 77-101. 
Curriculum for preschool. (2011, [1998]). Stockholm: The Swedish National Agency for Education

Denzin, N.K. (2009). The elephant in the living room: Or extending the conversation about the politics of evidence. Qualitative Research, 9(2), 139-160.

Einarsdóttir, J., Puroila, A-M., Johansson, E., Broström, S., \& Emilson, A. (2015). Democracy, caring and competence: Values perspectives in ECEC curricula in the Nordic countries. International Journal of Early Years, 23(1), 97-114.

Ellström, P-E. (2008). Knowledge creation through interactive research: A learning approach. Paper presented at the ECER Conference, Gothenburg, Sweden, 10-12th September, 2008.

Gadamer, H-G. (2004). Truth and method. New York: The Seabury Press.

Gadamer, H.G. (2006). Language and understanding. Theory, Culture \& Society, 23(1), 1327.

Greenwood, D., \& Lewin, M. (2007). Action research. Social research for social change. $2^{\text {nd }}$ edition. Thoudans Oaks, Ca: Sage.

Gunzenhauser, M.G. (2006). The moral epistemology of knowing subjects. Theorizing a relational turn for qualitative research. Qualitative Inquiry, 12(2), 621-647.

Johansson, E. (2003). Möten för lärande. Pedagogisk verksamhet för de yngsta barnen $i$ förskolan. [Encounters for learning. The pedagogical reality for the youngest children in preschools]. Skolverket, Forskning i fokus no 6. Stockholm: Fritzes.

Johansson, E., \& Emilson, A. (2016). Conflicts and resistance. Potentials for democracy learning in preschool. International Journal of Early Years Education, 24(1), 19-35.

Johanssoon, E., Puroila, A-M., \& Emilson, A. (2016). Research project overview: Values education in Nordic preschools - Basis of education for tomorrow. Special Issue: Values Education in Nordic Preschools: Theory and Practice. International Journal of Early Childhood, 48(2), 137-139.

Johansson, E., Emilson, A., Röthle, M., Puroila, A-M., Broström, S., \& Einarsdottir, J. (2016). Individual and collective rights expressed in educator and child interactions in Nordic preschools. Special Issue "Values education in Nordic preschools: theory and practice". International Journal of Early Childhood, 48(2), 209-224.

Johansson, J-E. (2010). Från pedagogik till ekonomi. Några kommentarer till kunskapsproduktionen i barnehagen. Nordisk barnehageforskning [Nordic Early Childhood Research], 3(3), 227-231.

Karila, K. (2012). A Nordic perspective on early childhood and care policy. European Journal of Education, 47(4), 584-595. 
Kemmis, S., \& McTaggart, R. (2005). Participatory Action Research. Communicative Action and the Public Sphere. In N.K. Denzin \& Y.S. Lincoln (Eds.), The Sage handbook of Qualitative Research, (pp. 559-603) (3th ed.). Thousand Oaks, California: Sage Publication Inc.

Kinsella, E. A. (2006). Hermeneutics and critical hermeneutics: Exploring possibilities within the art of interpretation. Forum: Qualitative social research, 7(3). http://www.qualitativeresearch.net/index.php/fqs/article/view/145/319\#g1 Accessed $29^{\text {th }}$ September 2016.

Kristjansson, B. (2006). The making of Nordic childhoods. In J. Einarsdottir, \& J.T. Wagner (Eds.), Nordic childhoods and early education (pp. 13-42). Greenwich, Connecticut: Information Age Publishing.

Laugharne, J., \& Baird, A. (2009). National conversations in the UK: using a language-based approach to interpret three key education policy documents (2001-2007) from England, Scotland and Wales. Cambridge Journal of Education, 39(2), 223-240.

Madsen, J. (2013). Narratives as a tool when working for equality in action research: A description and discussion of the researcher's experiences from a school development project in Norway. Educational Action Research, 21(3), 307-325.

McNess, E., Arthur, L., \& Crossley, M., (2015) 'Ethnographic dazzle' and the construction of the 'Other': Revisiting dimensions of insider and outsider research for international and comparative education. Compare: A Journal of Comparative and International Education, $45(2), 295-316$.

Milligan, L. (2016). Insider-outsider-inbetweener? Researcher positioning, participative methods and cross-cultural educational research. Compare: A Journal of Comparative and International Education, 46(2), 235-250.

Moss, P. (2007). Bringing politics into the nursery: Early childhood education as a democratic practice. European Early Childhood Education Research Journal, 15(1), 5-20.

Norden. (2016). Facts about the Nordic Region. Language. http://www.norden.org/en/faktaom-norden-1/language Accessed 8th August 2016.

Osborn, M. (2004). New methodologies for comparative research? Establishing 'constants' and 'contexts' in educational experience. Oxford Review of Education, 30(2), 265-285.

Pillay, N. (2002). The significance of Gadamer's hermeneutics for cross-cultural understanding. South-African Journal of Philosophy, 21(4), 330-344.

Pouliot, V. (2007). "Sobjectivism": Toward a constructivist methodology. International Studies Quarterly, 51(2), 359-384.

Puroila, A-M., Johansson, E., Estola, E., Emilson, A., Einarsdóttir, J., \& Broström, S. (2016). Interpreting values in the daily practices of preschools: A cross-cultural analysis. Special issue "Values education in Nordic preschools: Theory and practice". International Journal of Early Childhood, 48(2), 141-159. 
Regan, P. (2012). Hans-Georg Gadamer's philosophical hermeneutics: Concepts of reading, understanding and interpretation. META: Research in Hermeneutics, Phenomenology, and Practical Philosophy, 4(2), 286-303.

Ricoeur, P. (1988). Från text till handling: En antologi om hermeneutik [From text to action: An anthology on hermeneutics; P. Kemp \& B. Kristensson, Eds.]. Stockholm, Sweden: Symposium.

Rubinstein-Ávila, E. (2013). Accounting for - and owing up to - the messiness in crosscultural/linguistic qualitative research: Towards methodological reflexivity in South America's Internet cafés. International Journal of Qualitative Studies in Education, 26(8), 1041-1061.

Siljander, P. (2011). What are we looking for? - Pro critical realism in text interpretation. Journal of Philosophy of Education, 45(3), 493-510.

Suwankhong, D., \& Liamputtong, P. (2015). Cultural insiders and research fieldwork: Case examples from cross-cultural research with Thai people. International Journal of Qualitative Methods. 14(5), 1-7.

Tjeldvoll, A. (1998). Introduction. In A. Tjeldvoll (Ed.), Education and the Scandinavian welfare state in the year 2000. Equality, policy and reform (pp. xi-wviii). New York: Garland Publishing, Inc.

Wagner, J.T., \& Einarsdóttir, J., (2008). The good childhood: Nordic ideals and educational practice. International Journal of Educational Research, 47(5), 265-269.

Waisbord, S. (2016). Communication studies without frontiers? Translation and cosmopolitanism across academic cultures. International Journal of Communication, 10, 868-886. 